\title{
Correlation of Matrix Metalloproteinases and Tissue Inhibitors of Matrix Metalloproteinase Expression in lleal Carcinoids, Lymph Nodes and Liver Metastasis with Prognosis and Survival
}

\author{
Petra Voland ${ }^{a}$ Sophie Besiga ${ }^{a}$ Roland Rad ${ }^{a}$ Thomas Braun ${ }^{c}$ Dorothee M. Baur ${ }^{a}$ \\ Aurel Perren $^{b}$ Rupert Langer ${ }^{b}$ Heinz Höfler ${ }^{b} \quad$ Christian Prinz $^{a}$ \\ all. Medizinische Klinik und Poliklinik, Klinikum rechts der Isar, ${ }^{b}$ Institute of Pathology, Technical University of \\ Munich, and ${ }^{\mathrm{C}}$ Anatomical Institute, Ludwig Maximilian University, Munich, Germany
}

\section{Key Words}

Enterochromaffin cell $\cdot$ Carcinoid $\cdot$ Matrix

metalloproteinase $\cdot$ Tissue inhibitor of metalloproteinase

\begin{abstract}
Purpose: lleal carcinoids are gut epithelial tumors originating from serotonin-containing enterochromaffin (EC) cells. Therapeutic options for effectively inhibiting the growth and spread of metastatic carcinoids are still limited. We aimed to identify the role of matrix metalloproteinases (MMPs) and their endogenous tissue inhibitors (TIMPs) during tumor development and metastasis. Patients and Methods: Tissue samples were obtained from surgically treated patients. Expression of the EC-cell marker, vesicular monoamine transporter-1 (VMAT-1), was used to verify ileal carcinoids. We investigated the differential expression of MMP-2, 7, 9, 11, and 13 and their endogenous inhibitors (TIMP-1, 2, and 3) by quantitative real-time RT-PCR in 25 primary tumors, their corresponding lymph node metastases and/or liver metastases and matched normal mucosa. Results: Significantly increased expression of VMAT-1, MMP-2, MMP-11, TIMP-1 and TIMP-3 was determined by quantitative RT-PCR in EC-cell carcinoids compared to normal intestinal mucosa $(p<0.05)$. In contrast, MMP-2 and MMP-9 as well as TIMP-1, TIMP-2, and TIMP-3 expression in primary tumors of patients with liver metastases (M1) was significantly lower than in pa-
\end{abstract}

tients lacking liver metastases (M0). EC-cell tumors were significantly larger in the M1 group of tumors, while VMAT-1 expression was significantly decreased. We found an inverse correlation between tumor size and prognosis. Univariate analysis further revealed that decreased expression of VMAT-1, MMP-2 and TIMP-3 in primary tumors was significantly associated with a reduced survival time of the patients. Conclusion: Our data reveal that MMP-2 and TIMP-3 expression together with VMAT-1 expression are of potential prognostic and clinical value in ileal carcinoids.

Copyright $\odot 2008$ S. Karger AG, Basel

\section{Introduction}

Ileal carcinoids are usually composed of serotoninproducing enterochromaffin (EC) cells and belong to the well-differentiated neuroendocrine carcinomas of the gut. They represent the vast majority of the neuroendocrine tumors (NETs) of the ileum [1], as polypeptide YY-producing L-cell tumors and neurotensin-producing $\mathrm{N}$-cell tumors are exceptionally rare [2]. The major therapeutic challenges of EC-cell carcinoids are liver metastases which respond only very poorly to therapy [3]. Knowledge about the events during invasion and formation of metastases of EC-cell carcinoids is very limited. Prognosis of ileal carcinoids and patients' quality of life

\section{KARGER \\ Fax +4161306 1234 \\ E-Mail karger@karger.ch}

www.karger.com (c) $2008 \mathrm{~S}$. Karger AG, Basel

0028-3835/09/0891-0066\$26.00/0

Accessible online at:

www.karger.com/nen
Christian Prinz

II. Medical Department, Technical University of Munich

Ismaninger Strasse 22

DE-81675 Munich (Germany)

Tel. +49 894140 5973, Fax +49 894140 4905, E-Mail christian.prinz@lrz.tum.de 
correlate with the presence of metastases in the liver which depends on the size of the primary tumor. If the tumor is $<1 \mathrm{~cm}$, only $20-30 \%$ metastasize into the sentinel lymph nodes and eventually into the liver. If the size exceeds $2 \mathrm{~cm}$, there is a $80 \%$ probability of metastases in the lymph nodes and a $50 \%$ probability of metastases in the liver $[4,5]$. Therefore, during the course of tumor development, there might be a step of proteolytic dysregulation causing deranged ratios of proteases and their inhibitors which we sought to discover in the current project.

A family of proteases possibly involved in tumor invasion are matrix metalloproteinases (MMPs), which are physiologically expressed at low levels in chromaffin cells and other neuroendocrine cells, e.g. in the thyroid [6]. There are about 25 subtypes of MMPs, which are membrane-bound or secreted comprising collagenases (MMP$1,8,13$, and 18), gelatinases (MMP-2 and 9), stromelysins (MMP-3, 10, and 11), matrilysins (MMP-7 and 26), and membrane-type MMPs (MMP-14-17, 24, and 25) [7]. MMPs are involved in the physiological remodeling of tissues and they also play a role in tumor progression and metastasis $[6,8]$. Various MMPs have been shown to influence the initiation, invasion and metastasis of tumors $[8,9]$.

In the human organism, there are endogenous tissue inhibitors of MMPs, the TIMPs. Four TIMPs, found in almost all tissues and body fluids, have currently been characterized in humans and designated TIMP-1, 2, 3, and 4. TIMP-1, 2, and 4 are present in soluble forms, while TIMP-3 is bound to the extracellular matrix (ECM). The expression pattern of TIMP-4 differs from that of the other TIMPs. TIMP-4 mRNA is localized in the brain and heart of adult humans, as well as the ovary and skeletal muscle, suggesting a role as an important tissue-specific regulator of ECM remodeling [10]. The balanced activities of MMPs and TIMPs are involved in normal and pathological events such as wound healing, tissue remodeling, angiogenesis, invasion, tumorigenesis and metastasis. TIMPs turn out to be multifunctional proteins which regulate different processes through MMP-dependent as well as MMP-independent pathways that might even be paradoxical or controversial $[11,12]$.

Until now, only little is known about the role of MMPs and TIMPs in endocrine tumors. Carcinoids of the small intestine are a relatively rare tumor disease. This fact may cause a possible bias in the data achieved, thus presenting a limiting aspect to studies about this tumor entity. However, we have used quantitative real-time RT-PCR analysis of primary EC-cell carcinoids, lymph node metastases and liver metastases to examine the level and pattern of the expression of MMPs and TIMPs exactly. We investigated the association of these factors with the progression of EC-cell carcinoids and examined their usefulness as prognostic markers.

\section{Patients and Methods}

\section{Patient Characteristics and Specimens}

This retrospective study included patients first diagnosed and treated between 1992 and 2004 at the Klinikum rechts der Isar, Technical University of Munich, Germany. Tissue samples from 28 patients with ileal carcinoids with lymphatic and/or hepatic metastases were histological evaluated by 2 different histopathologists and were investigated after obtaining informed consent. To confirm tumor origin an evaluation of the expression of the marker protein for EC-cells, vesicular monoamine transporter-1 (VMAT-1), in the primary tumor was performed. As a negative control, two duodenal carcinoids were evaluated but not included in the study and further analysis. In our study, the cutoff value was set at 1,000 VMAT- 1 mRNA copies $/ 10^{6}$ GAPDH mRNA copies in the primary tumor since this level corresponded to the 99.9\% confidence interval. Three patients with ileal carcinoids were removed from the study because we did not find a VMAT-1 expression level above 1,000 VMAT-1 mRNA copies $/ 10^{6} \mathrm{GAPDH}$, in parallel with negative staining for VMAT-1, and negative staining for chromogranin and/or serotonin. Consequently, these 3 patients were removed from the study since the origin of those tumors could not be determined accurately as ileal EC-cell carcinoids. Thus, the work compares a homogenous group of 25 patients with ileal EC-cell carcinoids.

The included patients with primary tumors of ileal carcinoids were surgical treated, all of them showed lymphatic infiltration ( $\mathrm{n}=25$ lymph node positive). 10 patients had liver metastases, but liver tissue samples were only obtained in 8 patients by biopsy or during surgical removal ( $\mathrm{n}=10$, liver positive). All tumors were found to be well-differentiated according to the histological reports. 15 patients were female and 10 male. The average age at first diagnosis and surgery was $59 \pm 14$ (range 35-87) years. Further characteristics, e.g. additional therapy, TNM status, grading, etc., of the patients included in the study are summarized in table 1. TNM staging was performed following current guidelines for endocrine ileal tumors [13]. T1 was defined as tumors invading the mucosa or submucosa with diameters of $\leq 1 \mathrm{~cm}$. T2 was defined as tumors invading the muscularis propria or showing diameters of $>1 \mathrm{~cm}$; T3 = tumors invading the subserosa, and T4 = tumors invading the peritoneum and/or other organs; $\mathrm{m}=$ multiple tumors. As all patients presented lymph node metastases at the time of diagnosis, disease stage was at least IIIB for any T, N1, and M0 or stage IV for any T and any N or M1. Ki-67 staining was performed, positive cells were counted, and corresponding grading stages are listed in table 1 . Grading distinguishes between three grades: $\mathrm{G} 1=\mathrm{Ki}-67$ index $\leq 2 \%$; G2 $=\mathrm{Ki}-67$ index between $>2$ and $20 \%$, and $\mathrm{G} 3=\mathrm{Ki}-67$ index $>20 \%$. Most tumors had a Ki-67 index of $<2 \%$ and were thus well-differentiated. Three patients were lost during follow-up and defined as dropouts. Complete follow-up was available for 22 patients, of whom 8 died and 14 were still alive 
Table 1. Patient characteristics

\begin{tabular}{|c|c|c|c|c|c|c|c|c|c|c|c|c|c|c|c|c|c|}
\hline $\begin{array}{l}\text { Patient } \\
\text { No. }\end{array}$ & Ctx & Rtx & Dot & Som & Inf & pT1 & pT2 & pT3 & pT4 & $\mathrm{m}$ & $\begin{array}{l}\text { LN } \\
\text { N1 }\end{array}$ & M0 & M1 & $\begin{array}{l}\text { Disease } \\
\text { stage }\end{array}$ & G1 & G2 & $\begin{array}{l}\text { Tumor size } \\
\emptyset \mathrm{mm}\end{array}$ \\
\hline 1 & & & & & & & & & $\mathrm{x}$ & & $\mathrm{x}$ & & $\mathrm{x}$ & IV & $\mathrm{x}$ & & 30 \\
\hline 2 & & & & $\mathrm{x}$ & $\mathrm{x}$ & & $\mathrm{x}$ & & & & $\mathrm{x}$ & & $\mathrm{x}$ & IV & & $\mathrm{x}$ & 30 \\
\hline 3 & & & & $\mathrm{x}$ & & & $\mathrm{x}$ & & & & $\mathrm{x}$ & $\mathrm{x}$ & & IIIB & $\mathrm{x}$ & & 30 \\
\hline 5 & $\mathrm{x}$ & & & $\mathrm{x}$ & $\mathrm{x}$ & & & & $\mathrm{x}$ & & $\mathrm{x}$ & & $\mathrm{x}$ & IV & & $\mathrm{x}$ & 50 \\
\hline 6 & & & & & & $\mathrm{x}$ & & & & & $\mathrm{x}$ & $\mathrm{x}$ & & IIIB & $\mathrm{x}$ & & 4 \\
\hline 7 & & & & & & & & $\mathrm{x}$ & & $\mathrm{x}$ & $\mathrm{x}$ & $\mathrm{x}$ & & IIIB & $\mathrm{x}$ & & 10 \\
\hline 8 & & & & $\mathrm{x}$ & & & & $\mathrm{x}$ & & & $\mathrm{x}$ & & $\mathrm{x}$ & IV & & $\mathrm{x}$ & 15 \\
\hline 9 & & & & & & & $\mathrm{x}$ & & & $\mathrm{x}$ & $\mathrm{x}$ & $\mathrm{x}$ & & IIIB & $\mathrm{x}$ & & 15 \\
\hline 10 & & & & & & & $\mathrm{x}$ & & & & $\mathrm{x}$ & & $\mathrm{x}$ & IV & $\mathrm{x}$ & & 22 \\
\hline 14 & & & & & & & & & $\mathrm{x}$ & $\mathrm{x}$ & $\mathrm{x}$ & $\mathrm{x}$ & & IIIB & $\mathrm{x}$ & & 12 \\
\hline 15 & & & & & & & $\mathrm{x}$ & & & & $\mathrm{x}$ & $\mathrm{x}$ & & IIIB & & $\mathrm{x}$ & 15 \\
\hline 16 & & & & & & $\mathrm{x}$ & & & & & $\mathrm{x}$ & $\mathrm{x}$ & & IIIB & $\mathrm{x}$ & & 8 \\
\hline 17 & & & & & & & $\mathrm{x}$ & & & & $\mathrm{x}$ & & $\mathrm{x}$ & IV & $\mathrm{x}$ & & 15 \\
\hline 18 & & & & & & & $\mathrm{x}$ & & & $\mathrm{x}$ & $\mathrm{x}$ & $\mathrm{x}$ & & IIIB & & $\mathrm{x}$ & 15 \\
\hline 19 & & & & & & & $\mathrm{x}$ & & & & $\mathrm{x}$ & $\mathrm{x}$ & & IIIB & $\mathrm{x}$ & & 10 \\
\hline 20 & & & & & & & & $\mathrm{x}$ & & & $\mathrm{x}$ & $\mathrm{x}$ & & IIIB & $\mathrm{x}$ & & 13 \\
\hline 21 & & & & & & & $\mathrm{x}$ & & & & $\mathrm{x}$ & $\mathrm{x}$ & & IIIB & $\mathrm{x}$ & & 25 \\
\hline 22 & & & & & & & & $\mathrm{x}$ & & & $\mathrm{x}$ & $\mathrm{x}$ & & IIIB & $\mathrm{x}$ & & 20 \\
\hline 23 & & & & & & $\mathrm{x}$ & & & & & $\mathrm{x}$ & $\mathrm{x}$ & & IIIB & & $\mathrm{x}$ & 3 \\
\hline 24 & & & & & & & & $\mathrm{x}$ & & & $\mathrm{x}$ & $\mathrm{x}$ & & IIIB & $\mathrm{x}$ & & 15 \\
\hline
\end{tabular}

Additional therapies following surgery included chemotherapy (Ctx), radiation (Rtx), Dotatoc (Dot), Somatostatin analogs (Som), and interferon (Inf). The table describes tumor stage according to the TNM status, disease stage, grading according to Ki-67 index, and tumor size. $\mathrm{m}=$ Multiple tumors; $\mathrm{LN}=$ lymph node; Liv. met. = liver metastasis.

at the defined evaluation time point, April 1, 2007. Three of the 22 patients had to be classified as dropouts at 1 month (disease unrelated death), 26 and 28 months (last secure proof of life). None of the patients received additional medical treatment such as somatostatin analogs or chemotherapy before surgery, thus excluding an effect of additional treatment on the expression patterns.

\section{Tissue Preparation}

Under RNAse-free conditions, formalin-fixed paraffin-embedded tissue samples were sectioned at $10 \mu \mathrm{m}$, mounted on Super-Frost ${ }^{\circledR}$ Plus glass slides (Menzel GmbH \& Co. KG, Braunschweig, Germany) and processed without delay. Slides were dewaxed in two changes of xylene, rehydrated and stained with hematoxylin-eosin (HE) if necessary. Whole tissue or separated areas (tumor or normal mucosa) of the section was scraped off to extract total RNA. Because carcinoids are typically represented by densely packed tumor cells with a very small stromal part, it was possible to dissect the tumor tissue of each section from the normal mucosa. Tissue amounts per slide depended on tumor or tissue section size and lay between 300 and $50 \mathrm{~mm}^{2}$ in most cases. In 5 liver metastases where biopsies were taken, tissue amounts had a size of $25 \mathrm{~mm}^{2}$. Small amounts were balanced by the number of serial tissue sections used.

\section{RNA Extraction and cDNA Synthesis by RT-PCR}

Scraped-off tissue was immersed in $200 \mu l$ lysis buffer (Tris/ $\mathrm{HCl}$; $\mathrm{pH} 8.0 ; 0.1 \mathrm{mmol} / \mathrm{EDTA}, \mathrm{pH}$ 8.0; 2\% SDS, pH 7.3) and 500 $\mu \mathrm{g}$ proteinase $\mathrm{K}$ (Applichem, Darmstadt, Germany) and incubated for $16 \mathrm{~h}$ at $60^{\circ} \mathrm{C}$ until completely lysed. RNA was extracted by a classical phenol/chloroform method and precipitated with an equal volume of isopropanol, $0.1 \mathrm{vol}$ of $3 \mathrm{~mol} / \mathrm{l}$ sodium acetate and $20 \mu \mathrm{g}$ carrier glycogen (Roche, Mannheim, Germany) at $-20^{\circ} \mathrm{C}$ for a minimum of $2 \mathrm{~h}$. Subsequently, the RNA pellet was washed once in $70 \%$ ethanol, dried and resuspended in $20 \mu \mathrm{l}$ of RNAsefree water. The RNA was transcribed into cDNA using Superscript II Reverse Transcriptase (Invitrogen, Karlsruhe, Germany), according to manufacturer's instructions. 
Table 2. Sequences of primer and probes for quantitative RT-PCR analysis

\begin{tabular}{|c|c|c|c|}
\hline Gene & Forward primer & Reverse primer & Fluorogenic probe \\
\hline VMAT-1 & 5'-TTCCTGGCACTACTGGATGGA-3' & 5'-GAGTCCCCTTGGCACTCTCA-3' & 5'-CACTCCAGCTTTGCATCCTACAGCCTTC-3' \\
\hline MMP-7 & 5'-CGGGAGGCATGAGTGAGCTA-3' & 5'-GCATTTTTTGTTTCTGAGTCATAGAGA-3' & 5'-AGTGGGAACAGGCTCAGGACTATCTCAAGAG-3 \\
\hline MMP-9 & 5'-CAGACATCGTCATCCAGTTTGG-3' & 5'-CCGTCCTTCCCGTCGAA-3' & 5'-CGCGGAGCACGGAGACGGGTAT-3' \\
\hline MMP-11 & 5'-CTGGGATAGACACCAATGAGATTG-3' & 5'-TGGAGACCGCGTCAAAGG-3' & 5'-TGGAGCCAGACGCCCCGC-3' \\
\hline MMP-13 & 5'-GATGAAGATGATTTGTCTGAGGAAGA-3' & 5'-CGCGAGATTTGTAGGATGGTAGT-3' & 5'-CTCCAGTTTGCAGAGCGCTACCTGAGA-3' \\
\hline TIMP-2 & 5'-GCGTTTTGCAATGCAGATGT-3' & 5'-CGTTTCCAGAGTCCACTTCCTT-3' & 5'-TGATCAGGGCCAAAGCGGTCAGTG-3' \\
\hline TIMP-3 & 5'-GCTGGAGGTCAACAAGTACCAGTA-3' & 5'-GCACAGCCCCGTGTACATCT-3' & 5'-CTGCTGACAGGTCGCGTCTATGATGG-3' \\
\hline
\end{tabular}

Table 3. Summary of expression levels and significant differences of all investigated factors

\begin{tabular}{|c|c|c|c|c|c|c|c|}
\hline $\begin{array}{l}\text { RT-PCR } \\
\text { for the } \\
\text { following }\end{array}$ & $\begin{array}{l}\text { Normal } \\
\text { mucosa } \\
(\mathrm{n}=25)\end{array}$ & $\begin{array}{l}\text { Primary tumor } \\
(\mathrm{n}=25)\end{array}$ & $\begin{array}{l}\text { LN metastases } \\
(\mathrm{n}=24)\end{array}$ & $\begin{array}{l}\text { Liver } \\
\text { metastases } \\
(\mathrm{n}=8)\end{array}$ & $\begin{array}{l}\text { Primary tumor } \\
\text { vs. normal } \\
\text { mucosa, p value }\end{array}$ & $\begin{array}{l}\text { LN metastases } \\
\text { vs. normal } \\
\text { mucosa, p value }\end{array}$ & $\begin{array}{l}\text { Liver metastases } \\
\text { vs. normal } \\
\text { mucosa, p value }\end{array}$ \\
\hline MMP-2 & $122,410 \pm 21,854$ & $161,016 \pm 47,932$ & $46,460 \pm 10,165$ & $8,255 \pm 3,864$ & n.s. & $0.002^{\mathrm{a}}$ & $0.003^{\mathrm{a}}$ \\
\hline MMP-7 & $3 \pm 1$ & $4 \pm 3$ & $2 \pm 1$ & $37 \pm 15$ & n.s. & n.s. & n.s. \\
\hline MMP-9 & $690 \pm 196$ & $965 \pm 263$ & $9,302 \pm 3,624$ & $220 \pm 191$ & n.s. & 0.051 & n.s. \\
\hline MMP-11 & $1,729 \pm 474$ & $4,032 \pm 789$ & $5,463 \pm 1,251$ & $4,995 \pm 2,062$ & 0.005 & n.s. & n.s. \\
\hline MMP-13 & $208 \pm 108$ & $96 \pm 30$ & $142 \pm 66$ & $77 \pm 31$ & n.s. & n.s. & n.s. \\
\hline TIMP-1 & $2,123 \pm 472$ & $20,055 \pm 5,777$ & $14,457 \pm 3,163$ & $10,095 \pm 4,387$ & $<0.001$ & $<0.001$ & 0.038 \\
\hline TIMP-2 & $148,494 \pm 22,216$ & $302,094 \pm 64,847$ & $276,383 \pm 93,451$ & $54,251 \pm 5,004$ & n.s. & n.s. & n.s. \\
\hline TIMP-3 & $31,256 \pm 11,075$ & $87,007 \pm 26,340$ & $138,513 \pm 47,109$ & $29,107 \pm 9,940$ & 0.002 & 0.005 & n.s. \\
\hline VMAT-1 & $457 \pm 204$ & $222,288 \pm 77,008$ & $126,887 \pm 3,3810$ & $31,016 \pm 12,574$ & $<0.001$ & $<0.001$ & $<0.001$ \\
\hline
\end{tabular}

Expression levels of MMPs and TIMPs in normal mucosa, primary ileal carcinoids, lymph node (LN) metastases and liver metastases determined by quantitative RT-PCR. The table summarizes the results for all investigated factors and the significant expression differences found between cancer tissue and normal tissue. mRNA amounts were determined by quantitative RT-PCR and are presented as relative expression normalized to $10^{6} \mathrm{GAPDH}$ mRNA copies. Values are means $\pm \mathrm{SE}$.

a Downregulated.

\section{Quantitative RT-PCR}

Quantitative TaqMan ${ }^{\circledR}$ real-time RT-PCR was performed using the ABI PRISM 7700 sequence detection system (Applied Biosystems, Foster City, Calif.) as described previously [14, 15]. To equalize for different tissue amounts, mRNA copy numbers of all genes investigated were normalized to $10^{6}$ GAPDH mRNA copies obtained for each tissue sample. Using the constant expression level of the housekeeping gene GAPDH in human cells for normalization gives the relative copy numbers for each investigated gene. Primer and probe sequences are listed in table 2. PCR product lengths were $66-84 \mathrm{bp}$. Table 3 gives an overview of all results obtained by quantitative RT-PCR. To avoid potential problems caused by the use of formalin-fixed paraffin-embedded tissue we used a classical phenol/chloroform extraction followed by RNA precipitation that allows recovery of short RNA fragments.

\section{Immunohistochemistry}

For VMAT-1 staining, after deparaffinization of the tissue sections $(4 \mu \mathrm{m})$ of interest, endogenous peroxidase activity was quenched by pretreatment with $0.7 \%$ methanol and $6.4 \% \mathrm{H}_{2} \mathrm{O}_{2}$ in $0.01 \mathrm{M}$ phosphate-buffered saline (PBS; pH 7.4) for $20 \mathrm{~min}$. Next, tissue was unmasked by heating in the microwave oven for $15 \mathrm{~min}$ at $800 \mathrm{~W}$ and $15 \mathrm{~min}$ at $400 \mathrm{~W}$ in $10 \mathrm{mM}$ citric acid (pH 6.0), followed by incubation with $5 \%$ normal goat serum for $30 \mathrm{~min}$ and with a rabbit anti-human VMAT-1 antibody (Biotrend, Cologne, Germany) diluted 1:250 in 5\% normal goat serum overnight at $4{ }^{\circ} \mathrm{C}$. After further incubation with a biotinylated goat anti-rabbit antibody (Dianova, Hamburg, Germany) diluted 1:500 in 5\% normal goat serum for $2 \mathrm{~h}$ and with an $\mathrm{ABC}$ kit (Vector, Burlingame, Calif.) for $2 \mathrm{~h}$, immunoreaction was visualized by treatment with $0.09 \%$ diaminobenzidine and $0.03 \% \mathrm{H}_{2} \mathrm{O}_{2}$ in $0.05 \mathrm{M}$ Tris- $\mathrm{HCl}(\mathrm{pH} 7.6)$. For MIB-1 staining and Ki-67 index, the immunohistochemical staining was performed on an automated staining system (Ventana BenchMark, Ventana Medical Systems, Tucson, Ariz.). Antigen retrieval was performed by heating (CC1 mild, Ventana BenchMark). The primary antibody, a monoclonal mouse anti-human anti-Ki67-antigene for clone MIB-1 (Dako ChemMate, Glostrup, Denmark), was incubated for $20 \mathrm{~min}$ at a dilution of 1:100. Visualiza- 
tion was performed using the avidin-biotin complex method, which yielded a brown staining signal. The immunostainings for MIB1 were evaluated by counting all positive and negative tumor cell nuclei in a punch (1,500-2,000 tumor cells) and the staining index was indicated as the percentage of positive cells.

\section{Statistical Analysis}

Results are expressed as mean \pm SE. Data were analyzed by Mann-Whitney rank sum test, Kaplan-Meier survival analysis, and log-rank test for survival analysis, depending on the data set of concern. The cutoff between high and low expression of a parameter was defined as the middle value between the means of the $\mathrm{M} 0$ group and the $\mathrm{M} 1$ group. Values of $\mathrm{p} \leq 0.05$ were considered to be significant.

\section{Results}

\section{VMAT-1 Expression in Ileal Carcinoids}

VMAT-1 has previously been shown to be expressed predominantly in ileal carcinoids [16]; however, it is not expressed in all NETs. We therefore determined the presence of VMAT-1 in ileal carcinoids by semiquantitative RT-PCR and immunohistochemistry. Expression of the VMAT-1 was determined in 25 patients originally diagnosed with ileal carcinoids. In these 25 patients, VMAT-1 expression was evaluated in normal mucosa, primary tumors, lymph nodes and liver metastases by quantitative real-time RT-PCR, and the results are shown in table 4.

To determine VMAT-1 expression and distribution on the protein level in our patient population, we performed immunohistochemistry on sections of normal mucosa, primary tumor, lymph node and liver metastases. As shown in figure 1 for one representative patient, staining revealed single VMAT-1-positive EC cells distributed in the crypts of healthy ileal mucosa (fig. 1A). The compact primary tumors showed strong staining for VMAT-1 while the adjacent (non-tumor) mucosa showed only single positive EC cells (fig. 1B) confirming our findings obtained with quantitative RT-PCR analysis. The same was found in the lymph node metastasis (fig. 1C) and the liver metastasis (fig. 1D). The intensity of staining appeared to correlate with the expression levels of VMAT-1 since patients with strong VMAT-1 expression on RT-PCR levels also showed intense protein staining (fig. 1). However, semiquantitative evaluation of VMAT-1 staining with survival analysis was not performed due to the strong expression.

\section{Tumor Size and VMAT-1 Expression Correlate with M0 and M1 Status}

We next investigated the correlation between the size of the primary tumor and M0/M1 status of the patients.
Table 4. Expression of VMAT-1 in primary tumors and matched normal mucosa of all patients diagnosed with EC carcinoids

\begin{tabular}{rrr}
\hline Patient No. & Normal mucosa & Primary tumor \\
\hline 1 & 0 & 9,500 \\
2 & 106 & 8,190 \\
3 & 93 & 1,208 \\
4 & 88 & 10,796 \\
5 & 128 & 8,610 \\
6 & 313 & 117,480 \\
7 & 280 & 15,332 \\
8 & 45 & 1,044 \\
9 & 0 & 24,652 \\
10 & 334 & 1,091 \\
11 & 12 & 8,892 \\
12 & 63 & 142,877 \\
13 & 4,086 & 83,749 \\
14 & 73 & 187,562 \\
15 & 499 & $1,022,278$ \\
16 & 55 & 232,577 \\
17 & 98,756 \\
18 & 108 & 369,121 \\
19 & 271 & 159,330 \\
20 & 230 & $1,731,606$ \\
21 & 84 & 174,505 \\
22 & 357 & 394,825 \\
23 & 188 & 457,174 \\
24 & 3,550 & 71,802 \\
25 & 162 & 214,885 \\
\hline & 311 & \\
\hline
\end{tabular}

mRNA amounts were determined by quantitative RT-PCR and are presented as relative expression normalized to $10^{6}$ GAPDH mRNA copies. Values are means \pm SE.

We found that NETs which had already metastasized into the liver were significantly larger (Ø $26.2 \pm 3.3 \mathrm{~mm})$ than tumors in patients with no liver metastases $(\varnothing 13.8 \pm 1.8$ $\mathrm{mm}$; fig. 2A). Surprisingly, expression levels of VMAT-1 in primary tumors inversely correlated with the M0/M1 status (fig. 2B) and tumor size (fig. 2C). These data revealed that more malignant and advanced carcinoids show a larger tumor mass but simultaneously produce significantly less VMAT-1, indicating that tumor progression of NETs is accompanied by a loss of differentiated EC-cell function.

The Ki-67 index and the subsequent grading did not reveal any correlation with survival or the expression of the MMPs or TIMPs, neither as a continuous variable nor when divided into grades (data not shown).

\section{Expression of MMPs and TIMPs in Carcinoids}

The expression of MMPs and TIMPs was quantitatively determined in healthy mucosa, primary tumor and 

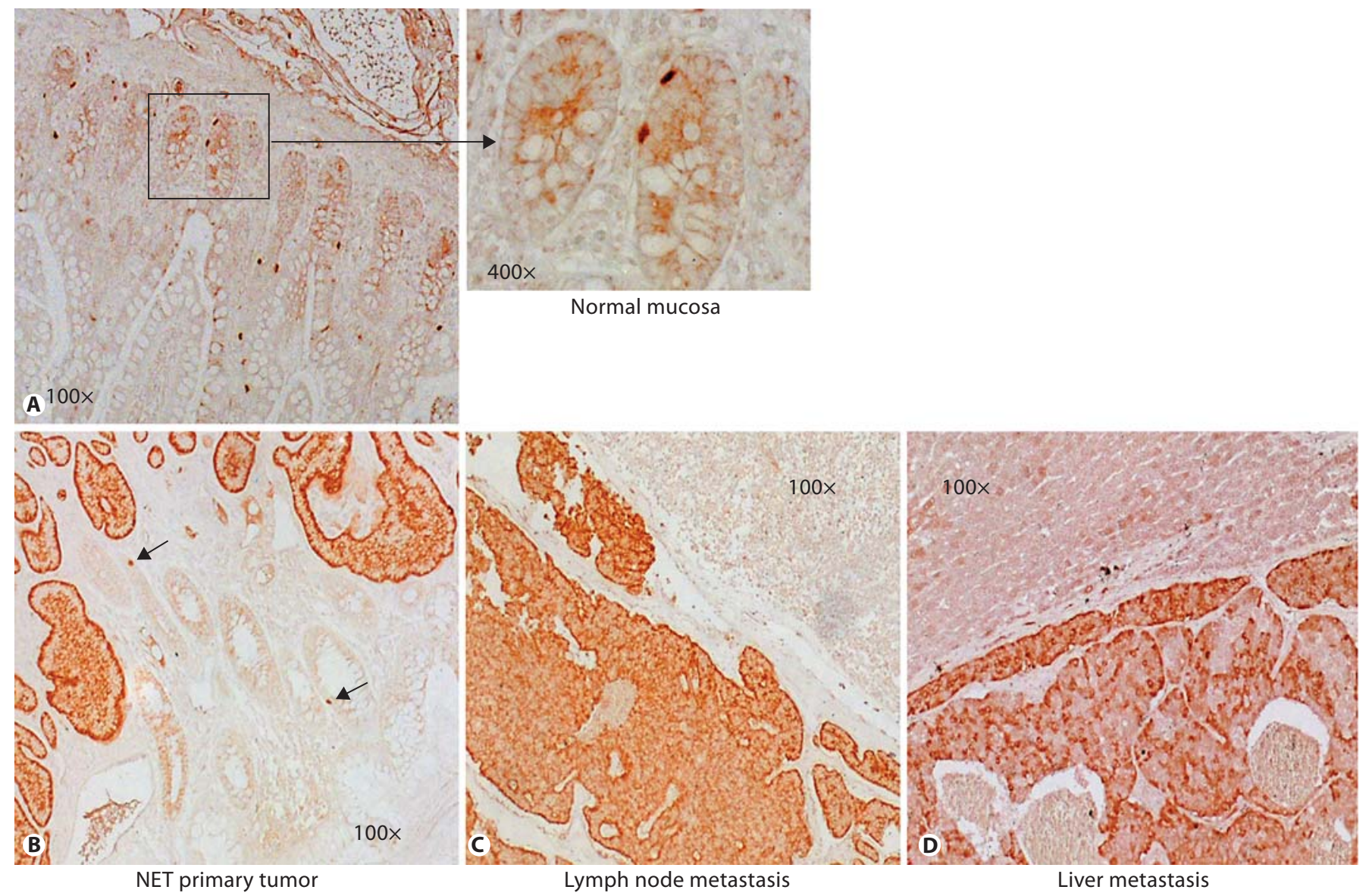

Fig. 1. VMAT-1 protein expression in neuroendocrine tumors and normal intestinal mucosa. Immunohistochemistry of tissue sections of one representative patient. A Staining with anti-VMAT-1 showed single positive EC cells distributed in the healthy ileal mucosa. B In the primary tumor a strong staining for VMAT-1 was found with the adjacent non-tumorous mucosa showing the typical diffuse distribution of single positive EC cells (arrows). C Lymph node staining revealed a strong positivity for VMAT-1 in the area of the tumor metastasis while adjacent healthy lymph node tissue was negative. D A similar picture was found in the liver metastasis with the tumor tissue being positive for VMAT-1 and the healthy liver tissue remaining negative. lymph node metastases matched for every patient. The specific MMPs and TIMPs were selected because of previous reports showing their differential expression and the prognostic impact of some of them in several solid tumors [17]. MMP-11 expression was found to be significantly increased in the tumor and even further elevated in lymph node metastases when compared to normal mucosa (fig. 3C). In contrast, MMP-2 expression was only slightly increased in tumor tissue and significantly decreased in the lymph nodes (fig. 3A), while MMP-9 was significantly increased only in lymph nodes (fig. 3B). MMP-7 and MMP-13 were not expressed at relevant levels and showed no notable differences in tumor tissues (table 3 ).

When analyzing the expression patterns of TIMPs, TIMP-1 and TIMP-3 were expressed significantly higher, both in the tumor and lymph node metastases compared to matched normal mucosa samples (fig. 3D, F). TIMP-2 also showed an increased expression in tumor tissue but this was not statistically significant (fig. 3E).

Table 3 summarizes the results for all investigated factors and significant expression differences detected. When comparing the expression levels of MMPs and TIMPs in liver metastases $(n=9)$ with normal mucosa samples, MMP-2 expression was significant decreased and TIMP-1 expression significant increased (table 3). Immunohistochemical staining for MMPs and TIMPs could not be established. 


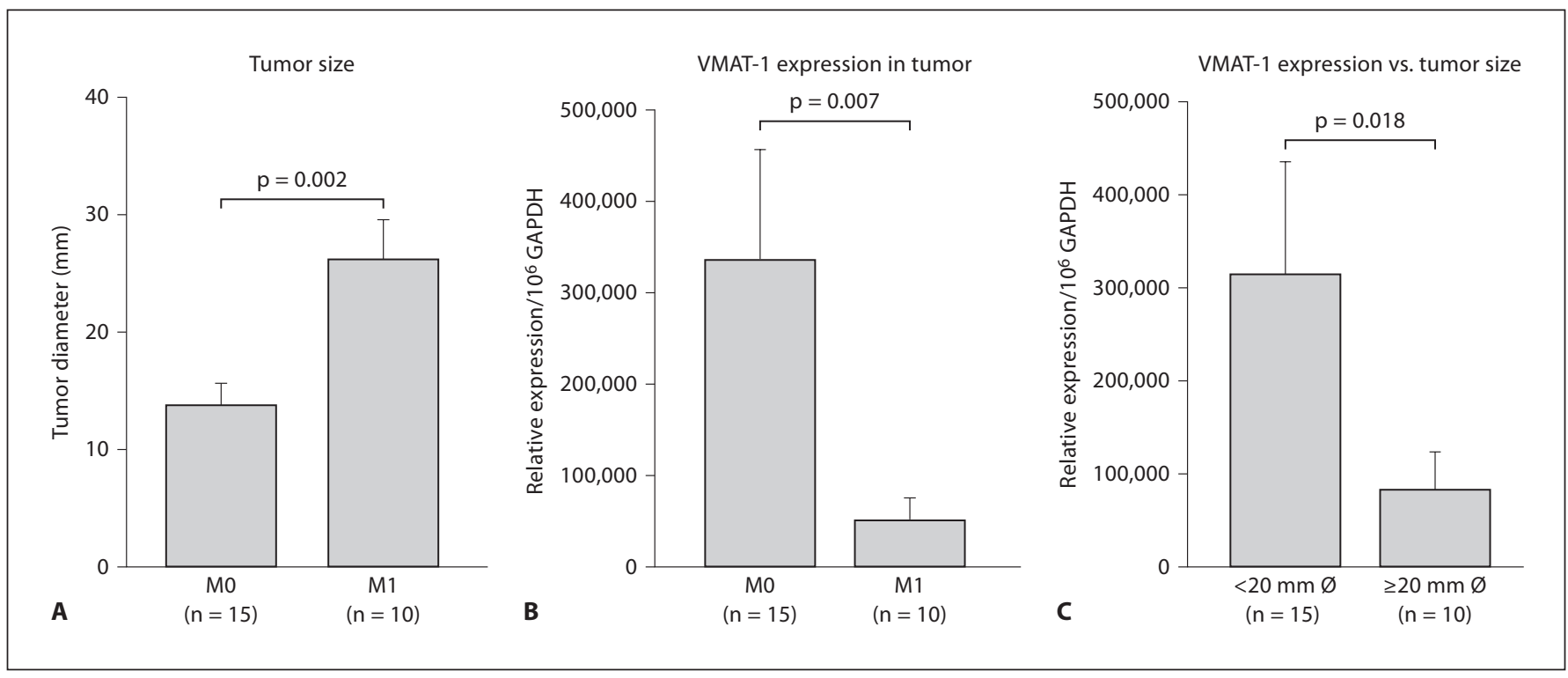

Fig. 2. Correlation of tumor size, VMAT-1 expression and status of liver metastasis. Patients without liver metastases (M0) are compared to patients with liver metastases (M1) regarding maximal primary tumor diameters in $\mathrm{mm}(\mathbf{A})$ and VMAT-1 expression in the tumor (B). C VMAT-1 expression levels in primary tumors sized $<20 \mathrm{~mm}$ maximal diameter are compared to expression levels in tumors sized $\geq 20 \mathrm{~mm}$. Expression was determined by quantitative RT-PCR and is shown as relative expression normalized to $10^{6} \mathrm{GAPDH}$ mRNA copies. Values are means $\pm \mathrm{SE}$.

\section{Correlation of MMP and TIMP Expression in}

Primary EC-Cell Tumors with M0/M1 Status

The prognosis of mid-gut carcinoids largely depends on the presence of metastases in the liver [4]. Therefore, we analyzed the expression patterns of MMPs and TIMPs in the primary tumors in correlation with the M0/M1 status of the patients. As depicted in figure 4, this revealed a significant downregulation of MMP-2 (fig. 4A, $\mathrm{p}=0.001$ ) and MMP-9 (fig. 4B, $\mathrm{p}=0.021$ ) expression and also a decreased MMP-11 expression in tumors with liver metastases (fig. 4C) compared to tumors of M0 status. When investigating the inhibitors of MMPs, we found that also the expression of TIMP-1, 2, and 3 was decreased in the primary tumors of patients with M1 status (fig. 4DF). This reduction in expression was even more pronounced and highly significant for all three TIMPs.

\section{Prognostic Relevance of MMP and TIMP Expression} in Patients with NETs

The most important question of this retrospective study finally was to determine whether prognostic factors for the survival of patients with ileal carcinoids can be defined. Survival analysis revealed a relationship between low expression of various factors and survival time after resection of the carcinoid independent of additive therapy. Decreased expression levels of MMP-2 (fig. 5B, $\mathrm{p}=0.017$ ) and TIMP-3 (fig. $5 \mathrm{D}, \mathrm{p}=0.02$ ) in the primary tumor correlated significantly with an unfavorable outcome of the disease. Also lower expression levels of VMAT-1 (fig. 5A) and TIMP-1 (fig. 5C) were indicative of poorer survival, but did not reach statistical significance, probably due to the relatively small patient population. As shown by the Kaplan-Meier plots in figure 5, patients with low expression levels of these factors in the primary tumor had a significantly shorter survival time than patients with high expression levels. In addition, our patient group exhibited the expected significant $(\mathrm{p}=0.015)$ association between survival time and status of liver metastases (M0/M1; data not shown).

\section{Discussion}

The current study aimed to identify factors associated with metastatic progression of ileal carcinoids. We investigated tumor size, stage of metastasis, grading by the Ki67 index and the expression of VMAT-1, a marker for EC cells [16], in 25 patients with ileal carcinoids, i.e. tumors originating from ileal EC cells, and correlated these parameters with each other and with survival. VMAT-1 lev- 


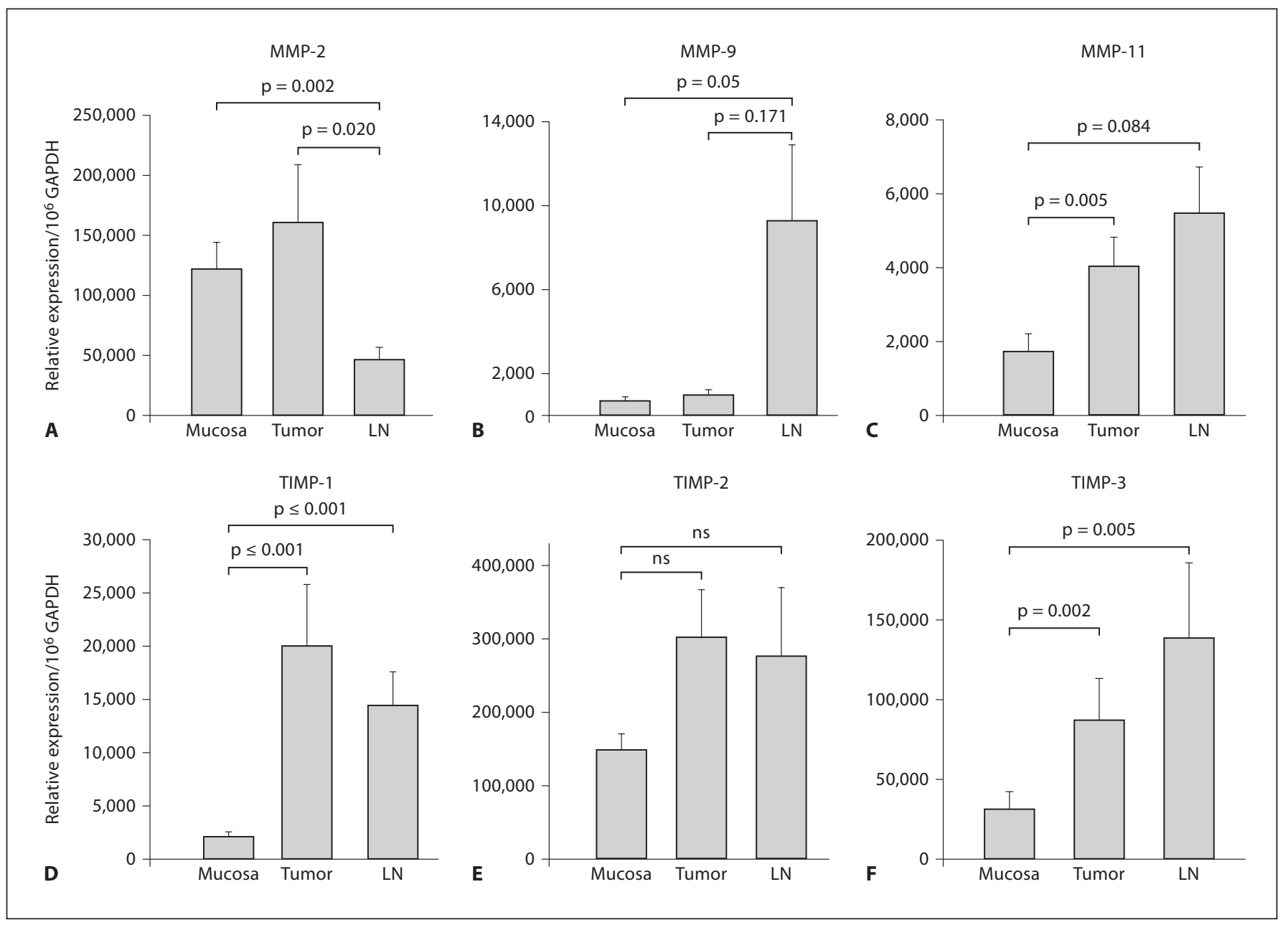

Fig. 3. Expression of MMPs and TIMPs in primary EC cell carcinoids and lymph node metastases in comparison to normal mucosa. Messenger RNA amounts were determined by quantitative RT-PCR for MMP-2 (A), MMP-9 (B), MMP-11 (C), TIMP-1 (D),
TIMP-2 (E), and TIMP-3 (F) in the indicated tissues and are presented as relative expression normalized to $10^{6} \mathrm{GAPDH}$ mRNA copies. Values are the means of $n=25$ patients \pm SE. $L N=$ Lymph node metastases. els were decreased in patients with liver metastases; VMAT-1 expression was inversely correlated with tumor size. We also observed a poor prognosis in patients with low VMAT-1 expression levels in the primary tumor. These observations support the hypothesis that tumors become more aggressive when the differentiated neuroendocrine phenotype is lost.

VMAT-1 is a transporter enabling the facilitated transport of serotonin into cytoplasmatic vesicles [18]. While gastric EC-like (ECL) cells express VMAT-2 responsible for the transport of histamine [19], VMAT-1 is present in EC cells producing serotonin [16]. Adrenal chromaffin cells express both transporters [20]. It has been shown that gastric ECL cell tumors can also be stained with an- tibodies against VMAT-2, and ileal carcinoids stain positive from VMAT-1 [16]. These proteins can therefore be used to differentiate different tumor entities. We were able to confirm the EC-cell origin of ileal carcinoids in contrast to two duodenal ECL cell carcinoids by VMAT-1 mRNA expression levels and immunohistochemical staining. VMAT-1 expression has also been detected in pheochromocytoma cells [21], however, contamination with these cells can be excluded.

In the study presented here, we were able to determine VMAT-1 expression in 25 patients with ileal EC-cell carcinoids. The strong expression proof that these 25 patients had ileal EC-cell carcinoids. It has to be mentioned that some tumors may be missed since not all ileal carci- 


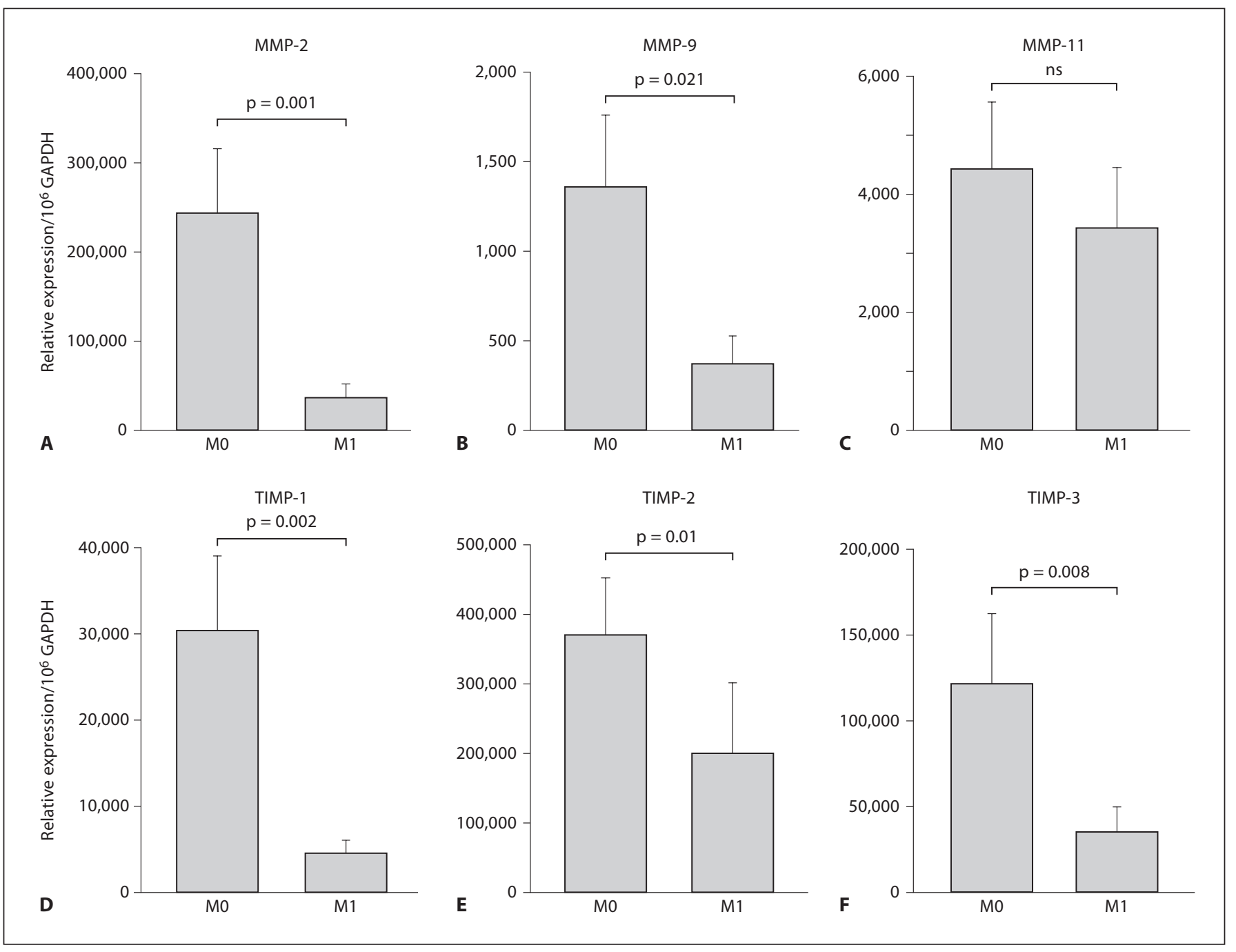

Fig. 4. MMP and TIMP expression in EC cell primary tumors in relation to hepatic metastasis status. The expression levels of MMP-2 (A), MMP-9 (B), MMP-11 (C), TIMP-1 (D), TIMP-2 (E), and TIMP-3 (F) in patients without liver metastasis (M0, $\mathrm{n}=15)$ are compared to the levels in patients with liver metastasis (M1, $\mathrm{n}=10$ ). mRNA amounts were determined by quantitative RTPCR and are presented as relative expression normalized to $10^{6}$ GAPDH mRNA copies. Values are means \pm SE. noids express this protein; however, in order to clearly determine the nature of the underlying cell type, tumors of potentially other origin were not further evaluated to guarantee a homogenous group of tumors was being compared with regard to their expression of MMP and their endogenous inhibitors.

Serotonin is an established marker for EC-cell carcinoids. But only about $85 \%$ of jejunoileal carcinoids have been shown to be positive for serotonin [22]. Consistent with this study, we found that 2 of the 25 tumors with a significant VMAT-1 expression were immunohistochemically negative for serotonin. These findings suggest a complementary role of VMAT-1 and serotonin as diagnostic tools in EC-cell tumors.

Our current study also investigated the role of expression patterns of several MMPs in mediating infiltration and metastasis of human ileal NETs. Only a few studies determined expression of MMPs and their endogenous inhibitors in digestive or pulmonary endocrine tumors by using immunohistochemistry [23, 24], but no information exists whether they are expressed in mid-gut carcinoids, and there is no study so far comparing expression levels with survival. MMP-2 has been previously reported to be a key protease for tissue destruction in the 

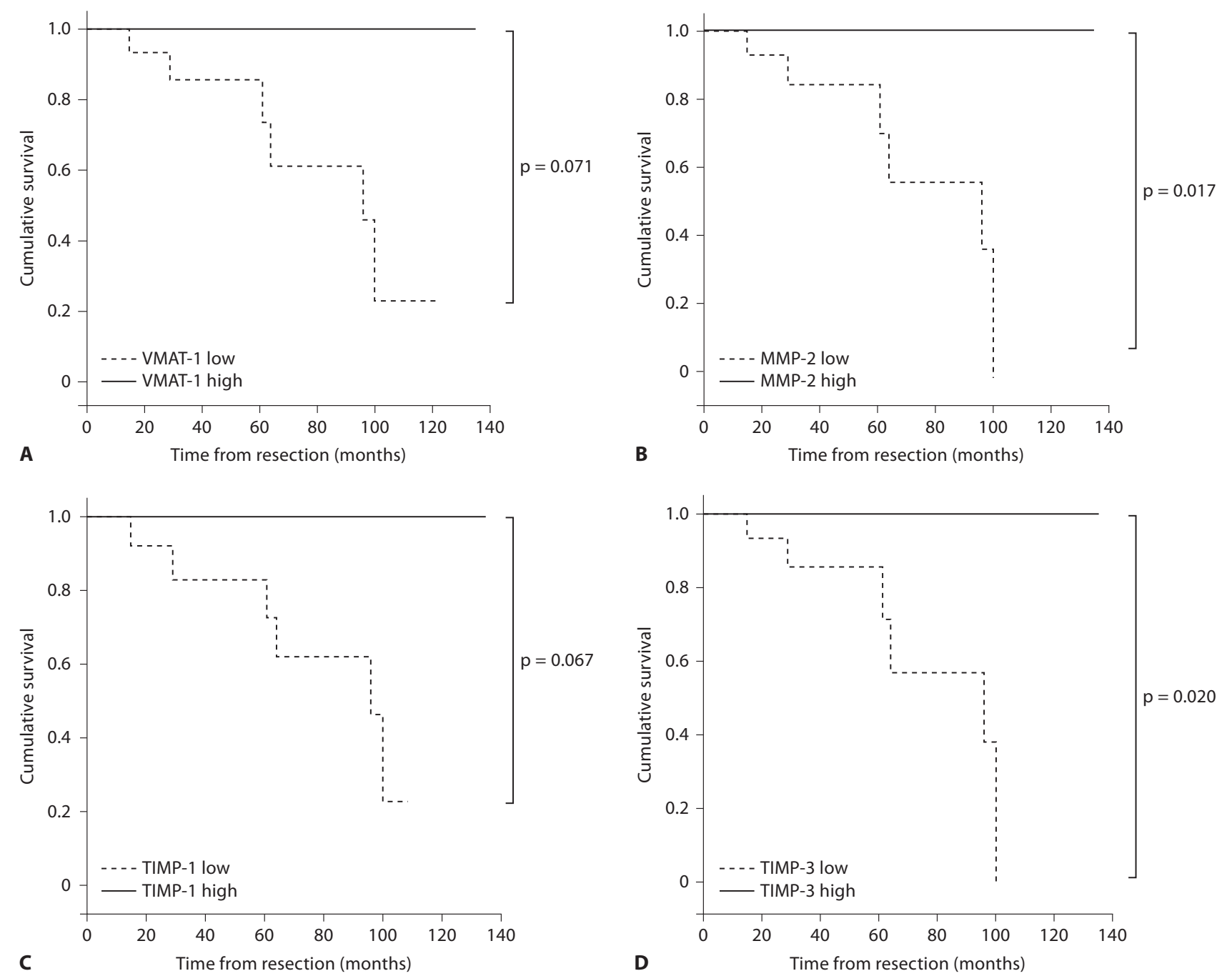

Fig. 5. Kaplan-Meier survival curve data showing correlation of survival and expression of VMAT-1, MMP-2, TIMP-1, and TIMP3 in the primary tumor. Survival data of patients with low expression is correlated with survival of patients with high expression of VMAT-1 (low $n=18$, high $n=7$, cutoff at 200.000 mRNA copies $/ 10^{6}$ GAPDH mRNA copies, A), MMP-2 (low $\mathrm{n}=17$, high $\mathrm{n}=$

8, cut ff at 150,000 mRNA copies $/ 10^{6}$ GAPDH mRNA copies, B), TIMP-1 (low $\mathrm{n}=15$, high $\mathrm{n}=10$, cutoff at 16,000 mRNA copies $/ 10^{6}$ GAPDH mRNA copies, C), and TIMP-3 (low $\mathrm{n}=17$, high $\mathrm{n}=8$, cutoff at $85,000 \mathrm{mRNA}$ copies $/ 10^{6}$ GAPDH mRNA copies, D). Survival time is indicated as time from resection in months.

gastrointestinal tract, thereby allowing tumor infiltration $[25,26]$. In our study, MMP-2 was highly expressed in primary NETs, suggesting a role for local tissue destruction and infiltration. When comparing the expression levels in the primary tumors of the patients with and without liver metastases, we found that patients with low expression levels had more frequent liver metastasis and a shorter survival time. The expression level of MMP-2

predicted survival and was a negative prognostic parameter in neuroendocrine carcinoids. These findings, however, are in contrast to observations made in many other gastrointestinal tumors and may be explained by the different cell phenotype. Increased levels of MMP-2 detected by immunohistochemistry, zymography, and RT-PCR have been found in gastric cancer [27], also correlating with a poor prognosis $[28,29]$. Other studies have report- 
ed increased MMP-2 expression in papillary thyroid carcinoma (immunohistochemistry) [30] and pancreatic cancer (Northern blot) [31] and a poor prognostic significance of increased MMP-2 expression in carcinomas of the kidney (immunohistochemistry) [32], the colon (Northern blot) [33], breast (immunohistochemistry) [34] and ovarian tumors (zymography) [35].

MMP-7 was not expressed at detectable levels and was therefore not a prognostic parameter in NETs of the ileum. MMP-7 is predominantly produced by epithelial cells [36]. In other cancer types, it has been shown that expression of MMP-7 correlates with the malignant potential of various gastrointestinal tumors and patient survival, for example in gastric cancer. Our data suggest that MMP-7 does not influence EC-cell tumor progression by regulating invasion and angiogenesis. Similarly, MMP-9 and MMP-11 were not of importance for predicting patient survival in ileal carcinoids.

MMP-9 and MMP-11 expression levels increased significantly with local tumor infiltration or lymph node metastasis, but were not prognostic markers regarding the overall survival or of the subgroup of patients with or without hepatic metastases. Increased MMP-9 expression has been found, e.g. in gastric cancer [25, 27], and inversely correlated with a prognostic significance in several different carcinomas, for example of the breast [34], ovary [35], kidney [32], and colon [33]. In pancreatic cancer, patients with MMP-11-positive carcinomas had a significantly shorter overall survival time than did those with MMP-11-negative carcinomas [37]. In our studies, we did not find these parameters to be important, outlining the observation that MMPs play a diverging role in intestinal adenocarcinoma and ileal carcinoids.

Of great importance, our study revealed that especially the expression patterns of the investigated TIMPs in invasive ileal carcinoids were of clinicopathological and prognostic value. While TIMP-1, 2 and 3 expression increased in tumor tissue and in part also in local lymph nodes (TIMP-3), we found that only reduced expression of TIMP-3 in the primary tumor indicated a poor prognosis. The correlation of TIMP-1-2 expression with survival showed divergent curves, but did not reach a statistically significant difference. In other studies, increased expression of MMP-2, TIMP-1 and 2 has been shown to correlate with a poor prognosis in renal cell carcinoma [32]. An inverse correlation was observed between TIMP2 and TIMP-3 expression levels and tumor grade in human pituitary tumors [38].

In metastasizing ileal carcinoids, we found that NETs with reduced TIMP-3 expression in the primary tumor had a very unfavorable impact on disease-free survival. In this regard, ileal carcinoids may share similarities with breast cancer cells because reduced expression of TIMP-3 within breast cancer cells was found to correlate with an aggressive tumor phenotype, negatively affecting the disease-free survival of both subgroups of lymph node-positive and mutant p53-negative patients [39]. Similar findings were reported in esophageal cancer where survival rates of patients with TIMP-3-negative cancer were significantly lower than those of TIMP-3-positive patients, and the mean 5 -year survival rates of patients with TIMP$3+,+/-$, and - were 50,58 , and $21 \%$, respectively [40]. Similar to our current results, the mean survival time of patients in that study was halved from 49 to 24 months in patients with reduced tumor TIMP-3 expression. These studies demonstrating the association between methylation of the TIMP-3 gene and esophageal cancer suggested that reduced differentiation might lead to methylation of the TIMP-3 gene resulting in reduced expression [41]. These findings are in close analogy with our current data in NETs.

The reasons for this inverse correlation may be as follows: TIMP-3 has also been described as a differentiation marker [42], whose biological activity is complex. timp$3^{-/-}$mice show a strong increase in liver and kidney metastasis induced by EL-4 lymphoma or B16F10 melanoma cells, underlining that TIMP-3 inhibits metastatic dissemination of diverse cancer cells [43]. Besides being an inhibitor for MMP-2, TIMP-3 acts as an inducer of apoptosis [42]. Thus, when expression levels of TIMP-3 in the ECM are decreased, cell proliferation and metastasis may be increased. Finally, TIMP-3 has been shown to be an inhibitor of angiogenesis via binding to the VEGFR-2 [44, 45]. Thus, increased vascularization of neuroendocrine metastases might occur when TIMP-3 expression is lowered. Strong vascularization is a typical feature of metastasizing ileal carcinoids $[4,46]$. Previous findings in midgut carcinoids using immunohistochemistry reported high VEGF-A levels [47], and VEGF-A expression predicted a poor outcome among well-differentiated NETs [48]. These data indicate that angiogenesis may be a key factor during neuroendocrine cell growth and metastasis. Further studies are currently being performed to clarify this issue.

It has to be emphasized that the current study evaluated the expression patterns of MMP/TIMPs in a small group of 25 patients which may limit the overall value of the results presented here, especially with regard to the complex picture of MMP/TIMP interaction. However, we believe that the significant differences observed here 
clearly show a differential expression pattern among the various parameters investigated. Due to the general scarcity of patients with this rare tumor disease, a larger sample number could not be achieved. It appears that a centralized acquisition of tissue samples from large tumor banks is reasonable and has to be pursued.

In summary, our studies reveal that MMP-2 and TIMP-3 expression in relation with VMAT-1 expression are prognostic markers and potentially of clinical value. Further research will determine the molecular mecha- nisms of tumor progression, aiming at possible new targets to suppress the aggressive spreading of these malignant tumors.

\section{Acknowledgements}

This work was supported by the Else Kröner-Fresenius-Stiftung. P.V. and S.B. contributed equally. Part of this work was performed by S.B. as a medical thesis for the Technical University of Munich.

\section{References}

1 Capella C, Heitz PU, Hofler H, Solcia E, Kloppel G: Revised classification of neuroendocrine tumours of the lung, pancreas and gut. Virchows Arch 1995;425:547-560.

2 Levy AD, Sobin LH: From the archives of the AFIP: gastrointestinal carcinoids: imaging features with clinicopathologic comparison. Radiographics 2007;27:237-257.

3 Zuetenhorst JM, Taal BG: Metastatic carcinoid tumors: a clinical review. Oncologist 2005; 10:123-131.

4 Hofler H, Stier A, Schusdziarra V, Siewert JR: Classification of neuroendocrine tumors of the gastrointestinal tract and pancreas and its therapeutic relevance (in German). Chirurg 1997;68:107-115.

5 Rindi G, Kloppel G, Alhman H, Caplin M, Couvelard A, de Herder WW, Erikssson B, Falchetti A, Falconi M, Komminoth P, Korner M, Lopes JM, McNicol AM, Nilsson O, Perren A, Scarpa A, Scoazec JY, Wiedenmann B: TNM staging of foregut (neuro)endocrine tumors: a consensus proposal including a grading system. Virchows Arch 2006;449:395-401.

6 Tomita T: Matrix metalloproteinases and tissue inhibitors of metalloproteinases in thyroid C-cells and medullary thyroid carcinomas. Histopathology 1997;31:150-156.

7 Visse R, Nagase H: Matrix metalloproteinases and tissue inhibitors of metalloproteinases: structure, function, and biochemistry. Circ Res 2003;92:827-839.

8 Hojilla CV, Mohammed FF, Khokha R: Matrix metalloproteinases and their tissue inhibitors direct cell fate during cancer development. Br J Cancer 2003;89:1817-1821.

9 Nagase H, Visse R, Murphy G: Structure and function of matrix metalloproteinases and TIMPs. Cardiovasc Res 2006;69:562-573.

10 Lambert E, Dasse E, Haye B, Petitfrere E: TIMPs as multifacial proteins. Crit Rev Oncol Hematol 2004;49:187-198.

11 Chirco R, Liu XW, Jung KK, Kim HR: Novel functions of TIMPs in cell signaling. Cancer Metastasis Rev 2006;25:99-113.
12 Jiang Y, Goldberg ID, Shi YE: Complex roles of tissue inhibitors of metalloproteinases in cancer. Oncogene 2002;21:2245-2252.

13 Rindi G, Kloppel G, Couvelard A, Komminoth P, Korner M, Lopes JM, McNicol AM, Nilsson O, Perren A, Scarpa A, Scoazec JY, Wiedenmann B: TNM staging of midgut and hindgut (neuro) endocrine tumors: a consensus proposal including a grading system. Virchows Arch 2007;451:757-762.

14 Rad R, Gerhard M, Lang R, Schoniger M, Rosch T, Schepp W, Becker I, Wagner H, Prinz C: The Helicobacter pylori blood group antigen-binding adhesin facilitates bacterial colonization and augments a nonspecific immune response. J Immunol 2002;168: 3033-3041.

15 Rad R, Brenner L, Bauer S, Schwendy S, Layland L, da Costa CP, Reindl W, Dossumbekova A, Friedrich M, Saur D, Wagner H, Schmid RM, Prinz C: CD25+/Foxp3+ T cells regulate gastric inflammation and Helicobacter pylori colonization in vivo. Gastroenterology 2006;131:525-537.

16 Jakobsen AM, Andersson P, Saglik G, Andersson E, Kolby L, Erickson JD, ForssellAronsson E, Wangberg B, Ahlman H, Nilsson O: Differential expression of vesicular monoamine transporter (VMAT) 1 and 2 in gastrointestinal endocrine tumours. J Pathol 2001; 195:463-472.

17 Curran S, Murray GI: Matrix metalloproteinases in tumour invasion and metastasis. J Pathol 1999;189:300-308.

18 Essand M, Vikman S, Grawe J, Gedda L, Hellberg C, Oberg K, Totterman TH, Giandomenico V: Identification and characterization of a novel splicing variant of vesicular monoamine transporter 1. J Mol Endocrinol 2005;35:489-501.

19 Prinz C, Zanner R, Gratzl M: Physiology of gastric enterochromaffin-like cells. Annu Rev Physiol 2003;65:371-382.
20 Erickson JD, Schafer MK, Bonner TI, Eiden LE, Weihe E: Distinct pharmacological properties and distribution in neurons and endocrine cells of two isoforms of the human vesicular monoamine transporter. Proc Natl Acad Sci USA 1996;93:5166-5171.

21 Huynh TT, Pacak K, Brouwers FM, bu-Asab MS, Worrell RA, Walther MM, Elkahloun AG, Goldstein DS, Cleary S, Eisenhofer G: Different expression of catecholamine transporters in phaeochromocytomas from patients with von Hippel-Lindau syndrome and multiple endocrine neoplasia type 2. Eur J Endocrinol 2005;153:551-563.

22 Burke AP, Thomas RM, Elsayed AM, Sobin LH: Carcinoids of the jejunum and ileum: an immunohistochemical and clinicopathologic study of 167 cases. Cancer 1997;79:10861093.

23 Pelosi G, Scarpa A, Veronesi G, Spaggiari L, Del CB, Moore PS, Maisonneuve P, Sonzogni A, Masullo M, Viale G: A subset of highgrade pulmonary neuroendocrine carcinomas shows up-regulation of matrix metalloproteinase-7 associated with nuclear beta-catenin immunoreactivity, independent of EGFR and HER-2 gene amplification or expression. Virchows Arch 2005;447:969977.

24 Tomita T, Iwata K: Gelatinases and inhibitors of gelatinases in pancreatic islets and islet cell tumors. Mod Pathol 1997;10:47-54.

25 Caenazzo C, Onisto M, Sartor L, Scalerta R, Giraldo A, Nitti D, Garbisa S: Augmented membrane type 1 matrix metalloproteinase (MT1-MMP):MMP-2 messenger RNA ratio in gastric carcinomas with poor prognosis. Clin Cancer Res 1998;4:2179-2186.

26 Mrena J, Wiksten JP, Nordling S, Kokkola A, Ristimaki A, Haglund C: MMP-2 but not MMP-9 associated with COX-2 and survival in gastric cancer. J Clin Pathol 2006;59:618623.

27 Nomura H, Sato H, Seiki M, Mai M, Okada Y: Expression of membrane-type matrix metalloproteinase in human gastric carcinomas. Cancer Res 1995;55:3263-3266. 
28 Allgayer H, Babic R, Beyer BC, Grutzner KU, Tarabichi A, Schildberg FW, Heiss MM: Prognostic relevance of MMP-2 (72-kD collagenase IV) in gastric cancer. Oncology 1998;55:152-160.

29 Kubben FJ, Sier CF, van DW, Griffioen G, Hanemaaijer R, van d, V, van Krieken JH, Lamers CB, Verspaget HW: Matrix metalloproteinase-2 is a consistent prognostic factor in gastric cancer. Br J Cancer 2006;94:10351040.

30 Korem S, Kraiem Z, Shiloni E, Yehezkel O, Sadeh O, Resnick MB: Increased expression of matrix metalloproteinase-2: a diagnostic marker but not prognostic marker of papillary thyroid carcinoma. Isr Med Assoc J 2002;4:247-251.

31 Gong YL, Xu GM, Huang WD, Chen LB: Expression of matrix metalloproteinases and the tissue inhibitors of metalloproteinases and their local invasiveness and metastasis in Chinese human pancreatic cancer. J Surg Oncol 2000;73:95-99.

32 Kallakury BV, Karikehalli S, Haholu A, Sheehan CE, Azumi N, Ross JS: Increased expression of matrix metalloproteinases 2 and 9 and tissue inhibitors of metalloproteinases 1 and 2 correlate with poor prognostic variables in renal cell carcinoma. Clin Cancer Res 2001;7:3113-3119.

33 Murashige M, Miyahara M, Shiraishi N, Saito T, Kohno K, Kobayashi M: Enhanced expression of tissue inhibitors of metalloproteinases in human colorectal tumors. Jpn J Clin Oncol 1996;26:303-309.

34 Li HC, Cao DC, Liu Y, Hou YF, Wu J, Lu JS, Di GH, Liu G, Li FM, Ou ZL, Jie C, Shen ZZ, Shao ZM: Prognostic value of matrix metalloproteinases (MMP-2 and MMP-9) in patients with lymph node-negative breast carcinoma. Breast Cancer Res Treat 2004;88: $75-85$.
35 Young TN, Rodriguez GC, Rinehart AR, Bast RC, Jr., Pizzo SV, Stack MS: Characterization of gelatinases linked to extracellular matrix invasion in ovarian adenocarcinoma: purification of matrix metalloproteinase 2 . Gynecol Oncol 1996;62:89-99.

36 Ii M, Yamamoto H, Adachi Y, Maruyama Y, Shinomura Y: Role of matrix metalloproteinase-7 (matrilysin) in human cancer invasion, apoptosis, growth, and angiogenesis. Exp Biol Med (Maywood) 2006;231:20-27.

37 Jones LE, Humphreys MJ, Campbell F, Neoptolemos JP, Boyd MT: Comprehensive analysis of matrix metalloproteinase and tissue inhibitor expression in pancreatic cancer: increased expression of matrix metalloproteinase-7 predicts poor survival. Clin Cancer Res 2004;10:2832-2845.

38 Beaulieu E, Kachra Z, Mousseau N, Delbecchi L, Hardy J, Beliveau R: Matrix metalloproteinases and their inhibitors in human pituitary tumors. Neurosurgery 1999;45: 1432-1440.

39 Mylona E, Magkou C, Giannopoulou I, Agrogiannis G, Markaki S, Keramopoulos A, Nakopoulou L: Expression of tissue inhibitor of matrix metalloproteinases (TIMP)-3 protein in invasive breast carcinoma: relation to tumor phenotype and clinical outcome. Breast Cancer Res 2006;8:R57.

40 Miyazaki T, Kato H, Nakajima M, Faried A, Takita J, Sohda M, Fukai Y, Yamaguchi S, Masuda N, Manda R, Fukuchi M, Ojima H, Tsukada K, Kuwano H: An immunohistochemical study of TIMP-3 expression in oesophageal squamous cell carcinoma. $\mathrm{Br}$ Cancer 2004;91:1556-1560.
41 Darnton SJ, Hardie LJ, Muc RS, Wild CP, Casson AG: Tissue inhibitor of metalloproteinase-3 (TIMP-3) gene is methylated in the development of esophageal adenocarcinoma: loss of expression correlates with poor prognosis. Int J Cancer 2005;115:351-358.

42 Gomez DE, Alonso DF, Yoshiji H, Thorgeirsson UP: Tissue inhibitors of metalloproteinases: structure, regulation and biological functions. Eur J Cell Biol 1997;74:111-122.

43 Cruz-Munoz W, Sanchez OH, Di GM, English JL, Hill RP, Khokha R: Enhanced metastatic dissemination to multiple organs by melanoma and lymphoma cells in timp3-/- mice. Oncogene 2006;25:6489-6496.

44 Anand-Apte B, Pepper MS, Voest E, Montesano R, Olsen B, Murphy G, Apte SS, Zetter $B$ : Inhibition of angiogenesis by tissue inhibitor of metalloproteinase-3. Invest Ophthalmol Vis Sci 1997;38:817-823.

45 Qi JH, Ebrahem Q, Moore N, Murphy G Claesson-Welsh L, Bond M, Baker A, nandApte B: A novel function for tissue inhibitor of metalloproteinases-3 (TIMP3): inhibition of angiogenesis by blockage of VEGF binding to VEGF receptor-2. Nat Med 2003;9: 407-415.

46 Turner HE, Harris AL, Melmed S, Wass JA: Angiogenesis in endocrine tumors. Endocr Rev 2003;24:600-632.

47 Terris B, Scoazec JY, Rubbia L, Bregeaud L, Pepper MS, Ruszniewski P, Belghiti J, Flejou J, Degott C: Expression of vascular endothelial growth factor in digestive neuroendocrine tumours. Histopathology 1998;32: 133-138.

48 Zhang J, Jia Z, Li Q, Wang L, Rashid A, Zhu Z, Evans DB, Vauthey JN, Xie K, Yao JC: Elevated expression of vascular endothelial growth factor correlates with increased angiogenesis and decreased progression-free survival among patients with low-grade neuroendocrine tumors. Cancer 2007;109:14781486. 